\title{
EFFECT OF FILLER ON THE AGING POTENTIAL OF ASPHALT MIXTURES
}

\author{
Miró Recasens, Rodrigo
}

Associate Professor, Technical University of Catalonia

Jordi Girona 1-3, Módulo B1, 08034 Barcelona, Spain

Phone 0034934017085, Fax 0034934017264

r.miro@upc.es

Martínez, Adriana

Associate Professor, Technical University of Catalonia

Jordi Girona 1-3, Módulo B1, 08034 Barcelona, Spain

Phone 0034934017273, Fax 0034934017264

adriana.martinez@upc.es

Pérez Jiménez, Félix

Professor, Technical University of Catalonia

Jordi Girona 1-3, Módulo B1, 08034 Barcelona, Spain

Phone 0034934017085, Fax 0034934017264

edmundo.perez@upc.es

Bianchetto, Hugo

Researcher, Universidad Nacional de La Plata

Calle 7 entre 47 y 48, 1900 La Plata, Argentina

Pone 00542214236687, Fax 00542214236687

hbianche@ing.unlp.edu.ar

Submission date: October 28, 2004. Review February 15, 2005.

Word count: $\quad 4,125$ words

3 tables $=750$ words

10 figures $=2,500$ words

Total $=7,375$ words

\begin{abstract}
In this work the effect filler has on the aging of bitumen is analyzed, but incorporating the filler in volume and not in weight. The UCL method is used as the process of accelerated aging and new direct tensile test is used to determine the toughness of the aged mixture and, thus, to assess the effect the filler has.

All the tests performed for this paper have shown the protective effect of the fillers used. The new direct tensile test developed by the Road Research Laboratory of the Technical University of Catalonia, allows to observe how an increase of filler produces the increase of the breaking load and the decrease of the maximum deformation, observing that the hydrated lime tends to stiffen the mixture less and make it less brittle than calcium carbonate.

In order to minimize the effect of aging on bitumen, the filler content proposed must be 20 or $30 \%$ less than the content recommended in conditions when there is no aging, so that when the mixture ages the mastic is able to build up the maximum energy possible.
\end{abstract}




\section{INTRODUCTION}

The processes that the binder undergoes when aging, which cause its progressive hardening, may damage its aggregate-bitumen adhesive qualities and, thus, the cohesion of the mixture.

The addition of filler to the mixture can improve adhesion and cohesion substantially (filler is a fine material, which passes a $0.063 \mathrm{~mm}$ sieve, derived from aggregate or other similar granular material). The bitumen-filler system (mastic), which is thicker and tougher than bitumen alone, improves the adhesive qualities and, in providing a covering film of greater thickness, also means that the aging processes can be slowed down. The effects of the addition of filler are directly related to their characteristics and the degree of concentration of the filler in the bitumen-filler system.

The advantages that filler offers for the durability of the bituminous mixtures in the case of water action are due, in principle, to its physical characteristics, reducing the porosity of the granular structure and thereby making the access of water and air difficult. Moreover, the chemical nature of filler may mean greater affinity with the asphalt binder, improving the resistance to the displacement that the water causes the bitumen.

Using immersion tests Craus, Ishai and Sides (1) assessed the influence that the type of filler had on the durability of the bituminous mixtures. The authors reviewed the usual criteria of mixture design, with analyses that simulate short periods of exposure to the environment (for example, for the case under study, the residual Marshall stability and the resistance of immersion-compression), noting that mixtures that pass these tests, usually fail completely in service. With the obtained results they were able to modify the existing criteria for the classification of fillers, which had only been based on basic properties without considering the durability factor. From this works, the authors have continued studying the effect of the characteristics of fillers on the durability of the mixtures (2).

Diverse methods of simulation of artificial aging have been developed in order to assess the durability of bituminous materials and mixtures. There are some very well known tests, which are performed on the binder, such as the TFOT, and the RTFOT, which attempt to reproduce short term aging, whereas others do it in the long term, like the PAV.

There are also diverse studies that use these procedures in order to assess the effect of filler in the aging of the binder. Thus, Petersen et al. (3), tried to quantify how the addition of filler might benefit the reduction of hardening by age and improve the properties of flow at low temperatures, using as a tool a variant of the RTFOT named Thin Film Accelerated Aging Test (TFAAT). They studied the physical-chemical behavior of mastics made with a conventional binder and three types of mineral fillings (lime with high calcium content, dolomitic lime and limestone dust). Firstly, they determined that the ideal filler-bitumen ratio in weight for the calcium lime is in the order of $20 \%$; then, they compared the behavior of the three fillers for this proportion. The conclusions must be confined to that limited number of variables, but they establish some comparative criteria according to which greater advantages are obtained when using calcium lime, whereas the use of limestone dust means little contribution as far as resistance to aging is concerned.

While trying to adapt the PAV test to age mastics, a study by Gubler et al. (4) in the Swiss Federal Laboratories arrived at a better understanding of how the addition of filler can delay the aging of binders: the particles of mineral filling are an obstacle to the diffusion of oxygen in the heart of the bitumen. A numerical model determined that around 55 grams of mastic were needed to obtain the same thickness of mastic film as of bitumen using the standardized method (which indicates the use of 50 grams of bitumen), due to its greater density. However, it was observed that the "obstacle" effect of the filler could compensate for the fact that the thickness of film is less if the specified 50 grams are used.

Nevertheless, a conceptual element is missing: the behaviour of one or various fillers is analyzed when they are added to the weight, ignoring the unequal filling effect that each of them have, which is clearly shown when comparisons are made in terms of volume.

In 1960, Ruiz (5) had already demonstrated the need to maintain the viscous properties of the bitumen filler system in order to guarantee that deformation does not occur with traffic and climatologic agents. Dorfman and Rivara (6) established the limit known as critical concentration. This is a volumetric concentration of filler in the bitumen-filler system from which increasingly greater dispersions of viscous fluid appear. An excess of filler leads to greater mixture stiffness and a loss of adhesive qualities.

As well as the methods of aging for bitumens, there are also methods of accelerated aging, which are applied directly to the bituminous mixture. Amongst these are STOA, for the short term, and LTOA for the long term. In addition to the above, we can also mention those of Lee et al. (7), which compare different methods of aging based on response of the binders. Synthesizing the obtained conclusions, STOA is a more rigorous process than the RTFOT, for the short term, while the PAV is a more rigorous process than LTOA, for the long term. 
The Universal de Caracterización de Ligantes method (UCL method) belongs to this latter group of aging methods. The UCL method is a method of characterization of binders developed by Pérez and Miró (8); the Cántabro test is used to measure the cohesion, which the binders give a standard mixture, without fines. The method allows us to assess the variation of this cohesion with the temperature, the action of water and aging. The last part of the method uses an aging process on a compacted mixture, like the LTOA, the difference being the mixture used; a standard mixture, without fines, of high porosity $(27 \pm 1 \%)$ that is heated in an oven at $80^{\circ} \mathrm{C}$ for different periods of time. The high porosity of the mixture allows the bitumen to age in the thin film, but in contact with the aggregate and we are thus able to assess the effect of aging directly on the mixture, without needing to extract the bitumen from the mixture $(9,10)$.

The aim of the work presented here, as with some of the above-mentioned publications, is to analyze the effect filler has on the aging of bitumen, but incorporating the filler in volume and not in weight. The UCL method is used as the process of accelerated aging and new direct tensile test is used to determine the toughness of the aged mixture and, thus, to assess the effect the filler has.

\section{METHODOLOGY}

In order to assess the effect the aging of the bitumen-filler system (mastic) has on the toughness that it gives to the standard mixture, a new direct tensile test has been selected, the Barcelona Tracción Directa test (BTD test), developed by Pérez and Miró $(11,12)$ in the Road Research Laboratory of the Technical University of Catalonia. The test consists of making a specimen in the Marshall moulds on a metal base made of two semicircles with a projection at the contact area, which creates a cleft in the central part of the specimen, and an anchoring system, compacted only on the upper surface (50 blows). The quantity of mixture needed is such that the height of the specimen above the base section is about $3 \mathrm{~cm}$. When the specimen is demoulded the notched base remains attached to the lower part and this means that clamps can be attached so force can be applied to tensile test, at a constant speed of deformation. During the test the opening of the cleft takes place, what causes the specimen to crack, as is shown in figures 1 and 2. The values registered are tensile effort applied and the opening of the cleft. In order to make the UCL standard mixture, granite aggregate was used with a special grading, table 1 . The bitumen used is a conventional penetration bitumen, $80-100$ penetration, with a constant content of $4.5 \%$ by mass of aggregate.

For the mastic, two with very different characteristics were chosen: calcium carbonate and hydrated lime. Firstly, its critical concentration was determined according to the standardized procedure.

The critical concentration corresponds to a dispersion of filler particles in the bitumen moving as freely as possible but in contact with each other, that is to say, when the applied stress is consumed in the viscous deformation of the continuous bitumen medium and the frictional resistance between particles is at a minimum. This particle arrangement is what is expected in the sediment and is obtained by settling a dispersion of filler in a fluid liquid medium with a chemical relationship with bitumens such as kerosene. The critical concentration is calculated with the following equation:

$$
C_{s}=\frac{P}{V . \gamma}
$$

where

$\mathrm{C}_{\mathrm{s}}=$ critical concentration

$\mathrm{P}=$ dry weight of filler $(\mathrm{g})$

$\mathrm{V}=$ settled volume of filler in anhydro kerosene after 24 hours $\left(\mathrm{cm}^{3}\right)$

$\gamma=$ specific weight of filler $\left(\mathrm{g} / \mathrm{cm}^{3}\right)$

The specific gravity of the hydrated lime is $2.351 \mathrm{~g} / \mathrm{cm}^{3}$ and its critical concentration is 0.165 ; the specific gravity of calcium carbonate is $2.771 \mathrm{~g} / \mathrm{cm}^{3}$ and its critical concentration is 0.370 .

These fillers were incorporated in the standard UCL mixture, in increasing volumetric concentrations $\left(\mathrm{C}_{\mathrm{v}}\right)$, with $\mathrm{C}_{\mathrm{v}} / \mathrm{C}_{\mathrm{s}}$ ratio of $0,0.5,1.0,1.3$ and 1,5 , where $\mathrm{C}_{\mathrm{v}} / \mathrm{C}_{\mathrm{s}}=0$ is the corresponding one to the reference mixture, without filler. Take note that the amounts added in weight are noticeably different for each one of the fillers, table 1 , which is why analyzing the same filler-bitumen ratio in weight (as recommended by the Spanish specifications, for example) would not make sense. Therefore, the addition of filler was made in volume and not in weight. Once the specimens of the mixture were made, on the notched bases, they were aged in oven at $80^{\circ} \mathrm{C}$ for $0,2,4$ and 7 days, the 0 day one being without accelerated aging, only undergoing the aging caused by the manufacture process.

The BTD direct tensile test was performed at $20^{\circ} \mathrm{C}$ and at a speed of deformation of $1 \mathrm{~mm} / \mathrm{min}$, slow enough to show the more or less ductile fracture of the mastics. The analyzed parameters were the critical load, the 
maximum deformation (obtained by means of the tangent straight line in the post-breaking zone of the curve load versus deformation) and the specific energy of fracture, obtained as the area of the load-displacement curve divided by the area of fracture of the specimen.

In addition, in the case of the lime, once the specimens were tested, the bitumen was then extracted. This was done so that its characteristics could be analyzed and compared with the original characteristics, so as to assess, in a more conventional way, the effect of this filler on the aging of the bitumen itself.

The bitumen extraction is made by centrifuge method using dichloromethane (ASTM D-2172-95, "A" method), at ambient temperature. Then, a distillation is performed using the Rotovapor apparatus (ASTM D-5404-93). The use of dichloromethane does not require a very initial high temperature (with dichloromethane it takes only $40^{\circ} \mathrm{C}$, while using trichloroethylene it takes $89^{\circ} \mathrm{C}$ ), and only the last 20 minutes the bitumen will remain at $163^{\circ} \mathrm{C}$ at a controlled pressure. In this way, the extraction and distillation processes do not affect the bitumen.

\section{ANALYSIS OF RESULTS}

Figures 3, 4, 5 and 6 show the development of the penetration, the softening point and the viscosity of the recovered bitumen of the standard mixture, which was aged over different periods of time. Moreover, it can be observed how the filler, in this case the hydrated lime, produces a smaller decrease in the penetration, a smaller increase in the softening point, as well as a smaller increase of viscosity, with respect to what happened to the bitumen of the reference mixture without filler.

These results demonstrate that the greater the amount of filler added, the less the bitumen ages. On the one hand this highlights the role of "protector" the filler has in the aging of the bitumen, but on the other hand it means the durability of the mixture cannot be assessed, since it is evident that high contents of filler mean a brittle mixture, that can quickly deteriorate. This means to say that it is not possible to establish a criterion for selecting the most suitable content of filler as far as the durability of the mixture is concerned. This indeed is the aim of the analysis of the effect of aging on the toughness of the mastic, using the BTD test.

Figure 7 shows as an example, the load-displacement curves obtained as the average for 3 specimens, for the reference mixture without filler and the different periods of aging. This figure shows how the breaking load tends to increase and the maximum deformation tends to decrease, clearly highlighting how the aging of the binder tends to stiffen the mixture, while at the same time it makes it increasingly more brittle.

In the following figures, 8 and 9, these same parameters are shown (breaking load and maximum deformation), for each of fillers analyzed, based on the different volumetric concentrations at which they were added to the standard mixture. In order to simplify the figures, only the values corresponding to the mixture aged for 7 days and the reference mixture, which was not aged (to 0 day) are represented. These values have been obtained, in general terms, from a mean of three individual results and the variation coefficients range between $3-12 \%$ for the breaking load, and $5-18 \%$ for the maximum deformation.

For calcium carbonate, the breaking load tends to increase as the volumetric concentration increases, until it reaches the value of 1.3 times the critical concentration, at which point the load no longer increases. On the other hand, the maximum deformation tends to diminish from $\mathrm{C}_{\mathrm{v}} / \mathrm{C}_{\mathrm{s}}=0.5$ point.

Although this happens as much for the mixture which has not been aged as for the aged one (the curves are very similar), the increase of the load and the decrease of the deformation are more marked for the mixture which has not been aged, which once again highlights the protective effect the filler has when bitumen ages. It is important to consider that the addition of filler causes a decrease of 7 points in the percentage of voids in the mixture which drops from 28 to $21 \%$ when the content is raised from 0 to 1.5 times the critical concentration. Table 3 .

The same tendencies as above are observed for the hydrated lime. However, neither the increase in the breaking load nor the decrease in the maximum deformation when the volumetric concentration is increased is as pronounced as it is for the calcium carbonate, both for the mixture which has been and the mixture which has not been aged. This could indicate that the protective effect of the hydrated lime against aging can be greater than that provided by calcium carbonate, especially if we take into account the fact that the porosity of the mixture is somewhat greater when hydrated lime is used, with a percentage of voids that only falls 2 points when it goes from $28 \%$ of the mixture without filler to $26 \%$ of the mixture with a hydrated lime content of 1.5 times its critical concentration. Table 3.

Nevertheless, using the figures above, it is difficult to establish a criterion for selecting the most suitable filler content from the point of view of the durability of the mixture. For this, figure 10 shows the variation of the specific energy of fracture with the volumetric concentration of incorporated filler, for each of the fillers used. For the calcium carbonate, with the mixture which has not been aged, we can see how the specific energy of fracture presents a maximum at $\mathrm{C}_{\mathrm{v}} / \mathrm{C}_{\mathrm{s}}=1.3$. However, the $\mathrm{C}_{\mathrm{v}} / \mathrm{C}_{\mathrm{s}}$ ratio for which the aged mixture is able to develop greater energy is slightly inferior, around 1.0. This means to say that, although the addition of filler, in this case calcium carbonate, protects the bitumen from aging, it seems that the amount to be added should be 
slightly less than the recommended ratio in conditions where there is no aging. When the $\mathrm{C}_{\mathrm{v}} / \mathrm{C}_{\mathrm{s}}$ ratio goes from 1.3 to 1.0 , it means a reduction of $20-30 \%$. Therefore, the optimum concentration to add to the mixture should be 20 or $30 \%$ less than the optimum defined by the non-aged curve.

For the hydrated lime, the mixture, which has not been aged, develops the maximum energy at the same concentration as the critical concentration $\left(\mathrm{C}_{\mathrm{v}} / \mathrm{C}_{\mathrm{s}}=1.0\right)$. This value coincides with the ideal one recommended in some specifications for the design of asphalt mixtures for this kind of filler (6). However, the ideal ratio for the mixture that has not been aged would be below this one (it is difficult in this case to give a specific value, although a reduction of 20 or $30 \%$ proposed in the case above, it seems to be adequate). The energy developed by the mixture with lime seems to be somewhat lower than that of the mixture with calcium carbonate, but the fact that the mixtures can not be compared directly as their porosity is not the same, must be taken into account.

\section{CONCLUSIONS}

All the tests performed for this paper have shown the protective effect of the fillers used, calcium carbonate and hydrated lime, against the aging of the bitumen. They have also shown the need to add the fillers to the mixture in volumetric concentrations and not in weight. Thus, their incorporation in increasing contents indicates a smaller decrease in the penetration, a smaller increase in the softening point and a smaller increase in the viscosity of the bitumen, indicators that aging is less.

Nevertheless, one of the properties which could be affected by the mastic aging, is the cracking resistance, which is generally ignored in the mixture design and characterization.

Therefore, a new direct tensile test was developed by the Road Research Laboratory of the Technical University of Catalonia. This test can demonstrate this protective effect, when assessing the increase of the breaking load and the decrease of the maximum deformation, observing that the hydrated lime tends to stiffen the mixture less and make it less brittle than calcium carbonate, in the same conditions of aging. This means to say that the lime has more protective effect than carbonate calcium.

However, the most important conclusion resulting from the study is that the specific energy of fracture which was assessed using the BTD test allows us to establish a criterion for selecting the ideal content of filler volume to be added to minimize the aging of the bitumen. In spite of the protective role of the filler, the content must be about 20 or $30 \%$ less than the content recommended in conditions when there is no aging, so that when the mixture ages the mastic is able to build up the maximum energy possible.

\section{REFERENCES}

1. Craus, J., I. Ishai, and A. Sides. Some physico-chemical aspects of the effect and role of the filler in bituminous paving mixtures. Journal of Association of Asphalt Paving Technologists, Vol. 47, 1978, pp. 558-587.

2. Ishai, I., and J. Craus. Effects of some aggregate and filler characteristics on behaviour and durability of asphalt paving mixtures. In Transportation Research Record: Journal of the Transportation Research Board, No. 1530, TRB, National Research Council, Washington, D.C., 1996, pp. 75-85.

3. Petersen, J., and P. Harnsberger. Asphalt aging: dual oxidation mechanisms and its interrelationships with asphalt composition and oxidative age hardening. In Transportation Research Record: Journal of the Transportation Research Board, No. 1638, TRB, National Research Council, Washington, D.C., 1998, pp. 47-55.

4. Gubler, R., Y. Liu, D. Anderson, and M. Partl. Investigation of the system filler and asphalt binders by rheological means. Journal of Association of Asphalt Paving Technologists, Vol. 68, 1999, pp. 284-302.

5. Ruiz, C.. Concentración crítica de filler, su origen y significado en la dosificación de mezclas abiertas. Dirección de Vialidad de la Provincia de Buenos Aires, Argentina, Publicación No 11, 1960.

6. Dorfman, B. and Y. Rivara. Sobre la utilización de filler en las mezclas asfálticas en caliente. X Congreso Argentino de Vialidad y Tránsito, Buenos Aires, 1985, pp. 467-484.

7. Lee, M., M. Tia, B. Ruth, and G. Page. Comparison between the aging processes for asphalt mixtures and those for asphalt binders. ASTM Special Technical Publication. No. 1322, 1997, pp. 126-136.

8. Pérez Jiménez, F., and R. Miró Recasens. Caractérisation mécanique de liants asphaltiques: méthode UCL. Proceedings of the Fifth International RILEM Symposium: Mechanical tests for bituminous materials, Lyon, 1997, pp.41-46. 
9. Pérez Jiménez, F., R. Miró Recasens, J. Sánchez Caba, and A. Páez Dueñas. Effect of ageing on rheological properties of modified bituminous binders. Eurobitumen Workshop, Luxemburg, 1999, Paper No. 100.

10. Miró Recasens, R., and F. Pérez Jiménez. Procedure for the evaluation of asphalt binders ageing in contact with aggregates and application of this procedure to analyze the influence of the aggregate type on binder ageing. International Journal of Road Materials and Pavement Design, Paris, Vol. 2, No. 1, 2001, pp. 97110.

11. Pérez Jiménez, F., R., Miró Recasens, and C. Fonseca. Essai BTD pour la détermination de la ténacité et résistance à la fissuration des mélanges bitumineux. Proceedings of the Fifth International RILEM Symposium: Mechanical tests for bituminous materials, Lyon, 1997, pp. 391-396.

12. Pérez Jiménez, F., R. Miró Recasens, and J. Cepeda Aldape. Analysis of fatigue performance of asphalt mixtures. Relationship between toughness and fatigue resistance. Proceedings of the Sixth International RILEM Symposium: Performance testing and evaluation of bituminous materials, Zurich, 2003, pp. 372379.

List of tables and figures

TABLE 1. Standard UCL mixture design.

TABLE 2. Characteristics and contents of filler used in the study.

TABLE 3. Air voids content and densities of the mixtures.

FIGURE 1. BTD test. Specimen notched with the special bases.

FIGURE 2. BTD test. Testing of the specimen.

FIGURE 3. Penetration of bitumen recovered from lime mixture with different periods of aging and different filler contents.

FIGURE 4. Softening point of bitumen recovered from lime mixture with different periods of aging and different filler contents.

FIGURE 5. Dynamic viscosity at $60^{\circ} \mathrm{C}$ of bitumen recovered from lime mixture with different periods of aging and different filler contents.

FIGURE 6. Dynamic viscosity at $135^{\circ} \mathrm{C}$ of bitumen recovered from lime mixture with different periods of aging and different filler contents.

FIGURE 7. Load-displacement curves by BTD test for different periods of aging (mixture without filler).

FIGURE 8. Variation of the breaking load with the volumetric concentration of filler for 0 and 7 days of aging. FIGURE 9. Variation of the maximum deformation with the volumetric concentration of filler for 0 and 7 days of aging.

FIGURE 10. Variation of the specific energy of fracture with the volumetric concentration of filler for 0 and 7 days of aging. 
TABLE 1. Standard UCL mixture design.

\begin{tabular}{lccc}
$\begin{array}{l}\text { Grading } \\
\text { Sieve }(\mathbf{m m})\end{array}$ & $\begin{array}{c}\text { Passing } \\
(\mathbf{\%})\end{array}$ & $\begin{array}{c}\text { Bitumen content } \\
(\% \text { of aggregate) }\end{array}$ & $\begin{array}{c}\text { Air voids content } \\
(\%)\end{array}$ \\
\hline 5 & 100 & & \\
2.5 & 20 & 4.5 & $27 \pm 1$ \\
0.63 & 0 & & \\
\hline
\end{tabular}


TABLE 2. Characteristics and contents of filler used in the study.

\begin{tabular}{lccccc} 
Filler type & $\begin{array}{c}\text { Specific } \\
\text { gravity } \\
\left(\mathbf{g} / \mathbf{c m}^{\mathbf{3}}\right)\end{array}$ & $\begin{array}{c}\text { Critical } \\
\text { concentration }\end{array}$ & $\begin{array}{c}\text { Cv/Cs } \\
\text { Ratio }\end{array}$ & $\begin{array}{c}\text { Filler } \\
\text { content } \\
\text { (g) }\end{array}$ & $\begin{array}{c}\text { Filler/bitumen } \\
\text { Ratio } \\
\text { (in weight) }\end{array}$ \\
\hline Hydrated Lime & 2.351 & 0.165 & 0.5 & 5.1 & 0.21 \\
& & & 1.0 & 11.2 & 0.46 \\
& & & 1.3 & 15.2 & 0.63 \\
Calcium carbonate & 2.771 & 0.370 & 1.5 & 18.7 & 0.77 \\
& & & 0.5 & 14.8 & 0.61 \\
& & & 1.0 & 35.5 & 1.46 \\
& & & 1.3 & 58.0 & 2.39 \\
& & & 1.5 & 80.0 & 3.29 \\
\hline
\end{tabular}


TABLE 3. Air voids content and densities of the mixtures.

\begin{tabular}{lccc} 
Filler type & $\begin{array}{c}\text { Cv/Cs } \\
\text { Ratio }\end{array}$ & $\begin{array}{c}\text { Air voids } \\
\text { content } \\
\mathbf{( \% )}\end{array}$ & $\begin{array}{c}\text { Density } \\
\left(\mathbf{g} / \mathbf{c m}^{\mathbf{3}}\right)\end{array}$ \\
\hline Without filler & 0 & 27.9 & 1.776 \\
Hydrated Lime & 0.5 & 27.2 & 1.815 \\
& 1.0 & 26.4 & 1.834 \\
& 1.3 & 25.9 & 1.844 \\
& 1.5 & 26.0 & 1.842 \\
Calcium carbonate & 0.5 & 25.9 & 1.832 \\
& 1.0 & 22.6 & 1.921 \\
& 1.3 & 21.1 & 1.964 \\
& 1.5 & 20.9 & 1.976 \\
& & & \\
\end{tabular}


FIGURE 1. BTD test. Specimen notched with the special bases. 
FIGURE 2. BTD test. Testing of the specimen.

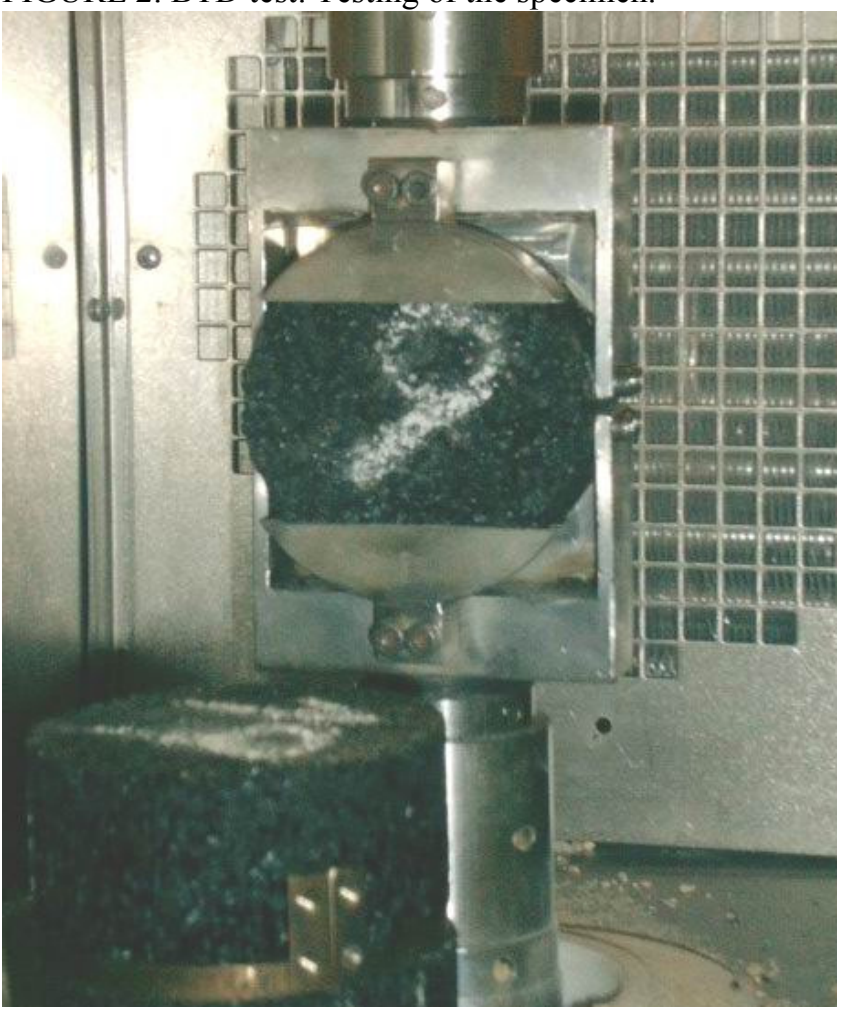


FIGURE 3. Penetration of bitumen recovered from lime mixture with different periods of aging and different filler contents (aging temperature: $80^{\circ} \mathrm{C}$ ).

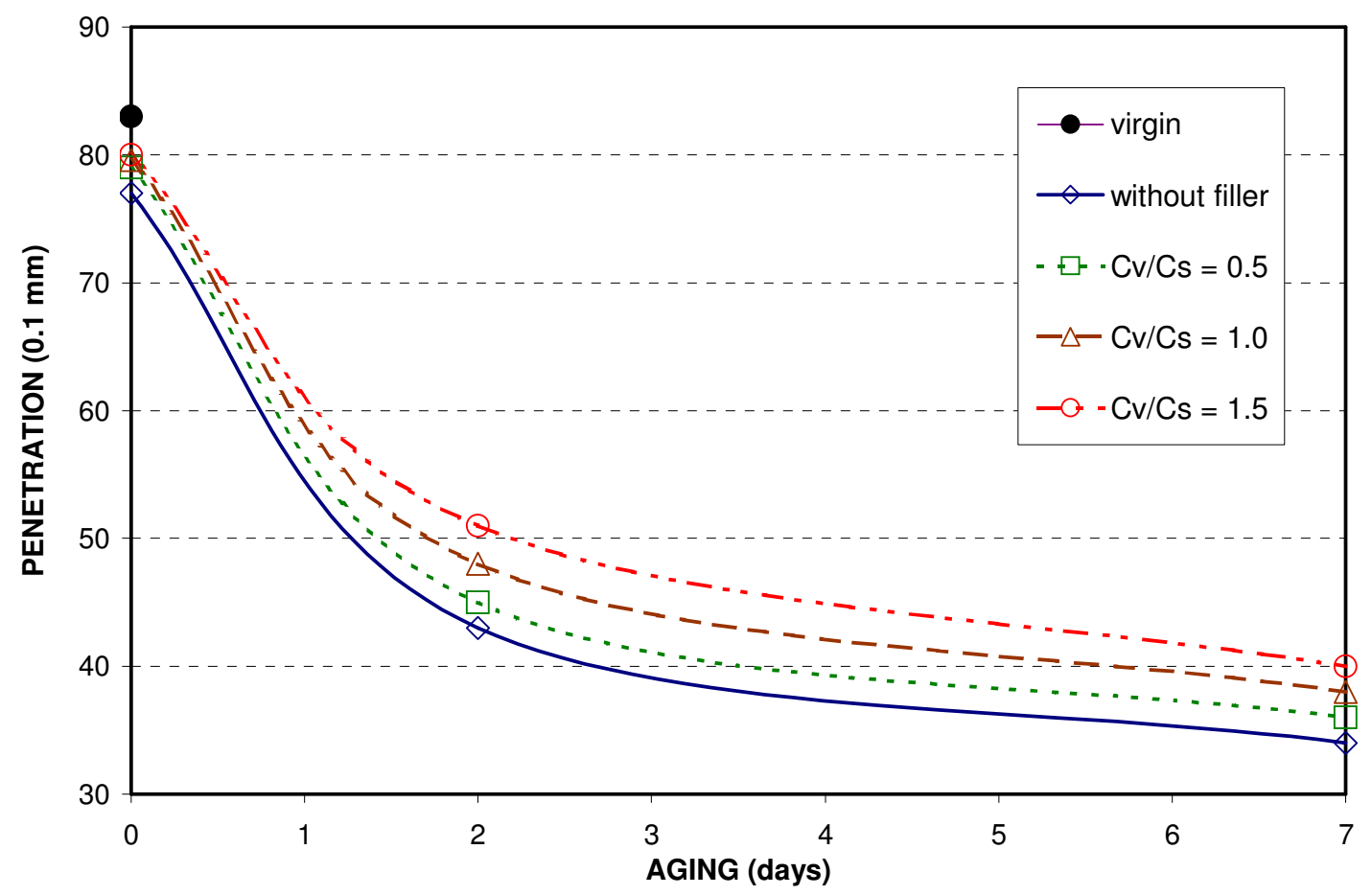


FIGURE 4. Softening point of bitumen recovered from lime mixture with different periods of aging and different filler contents (aging temperature: $80^{\circ} \mathrm{C}$ ).

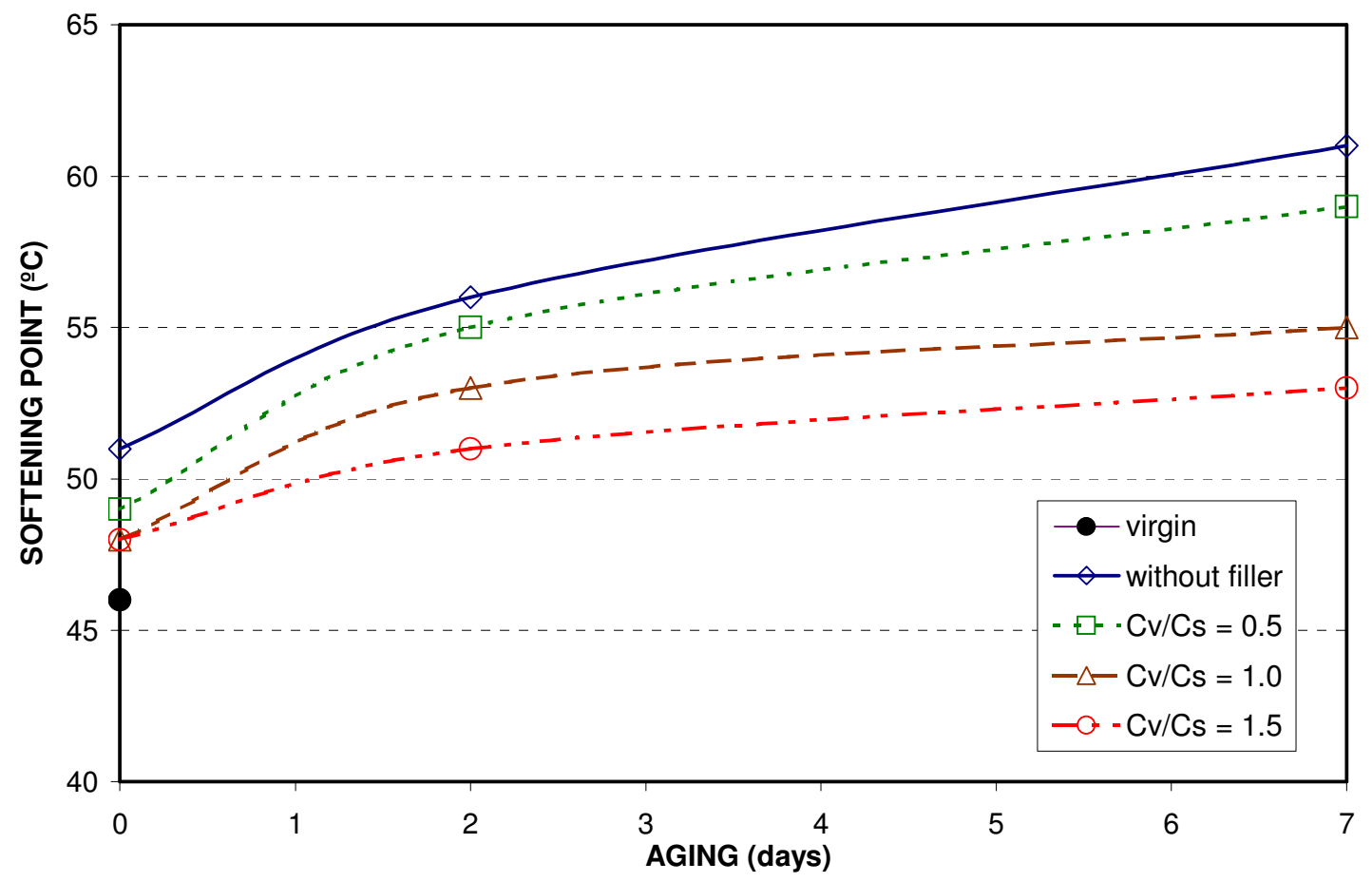


FIGURE 5. Dynamic viscosity at $60^{\circ} \mathrm{C}$ of bitumen recovered from lime mixture with different periods of aging and different filler contents (aging temperature: $80^{\circ} \mathrm{C}$ ).

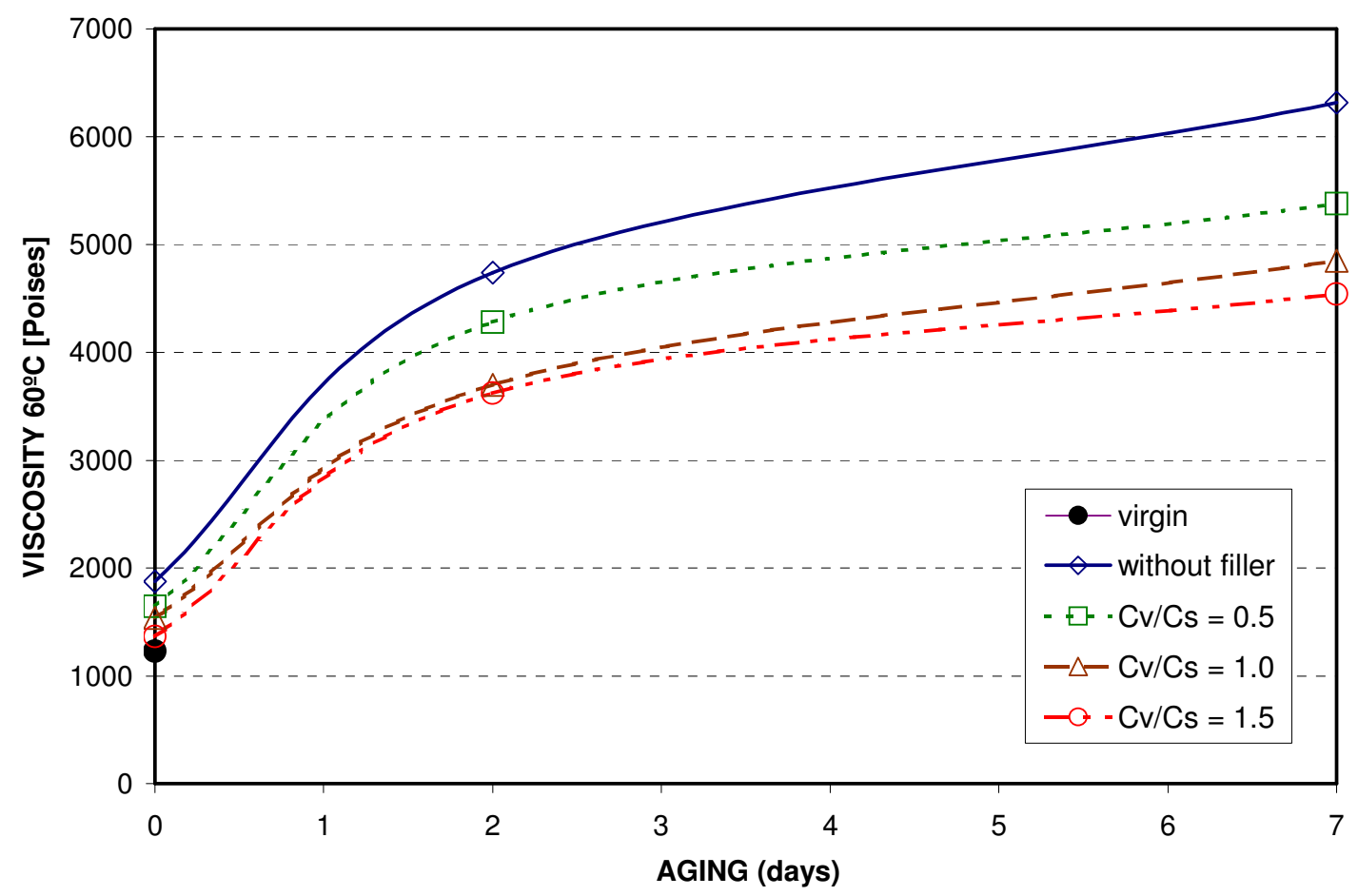


FIGURE 6. Dynamic viscosity at $135^{\circ} \mathrm{C}$ of bitumen recovered from lime mixture with different periods of aging and different filler contents (aging temperature: $80^{\circ} \mathrm{C}$ ).

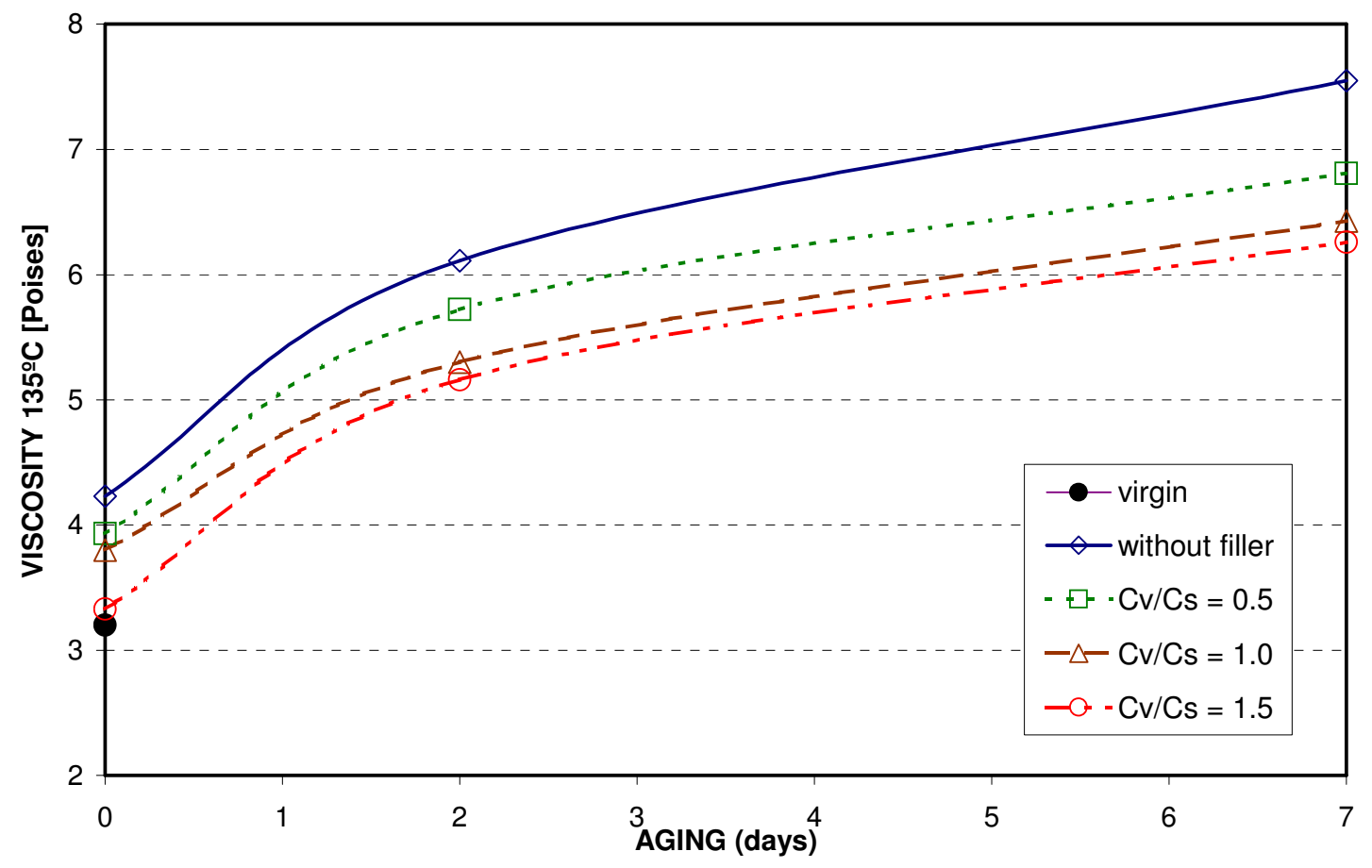


FIGURE 7. Load-displacement curves by BTD test for different periods of aging (mixture without filler).

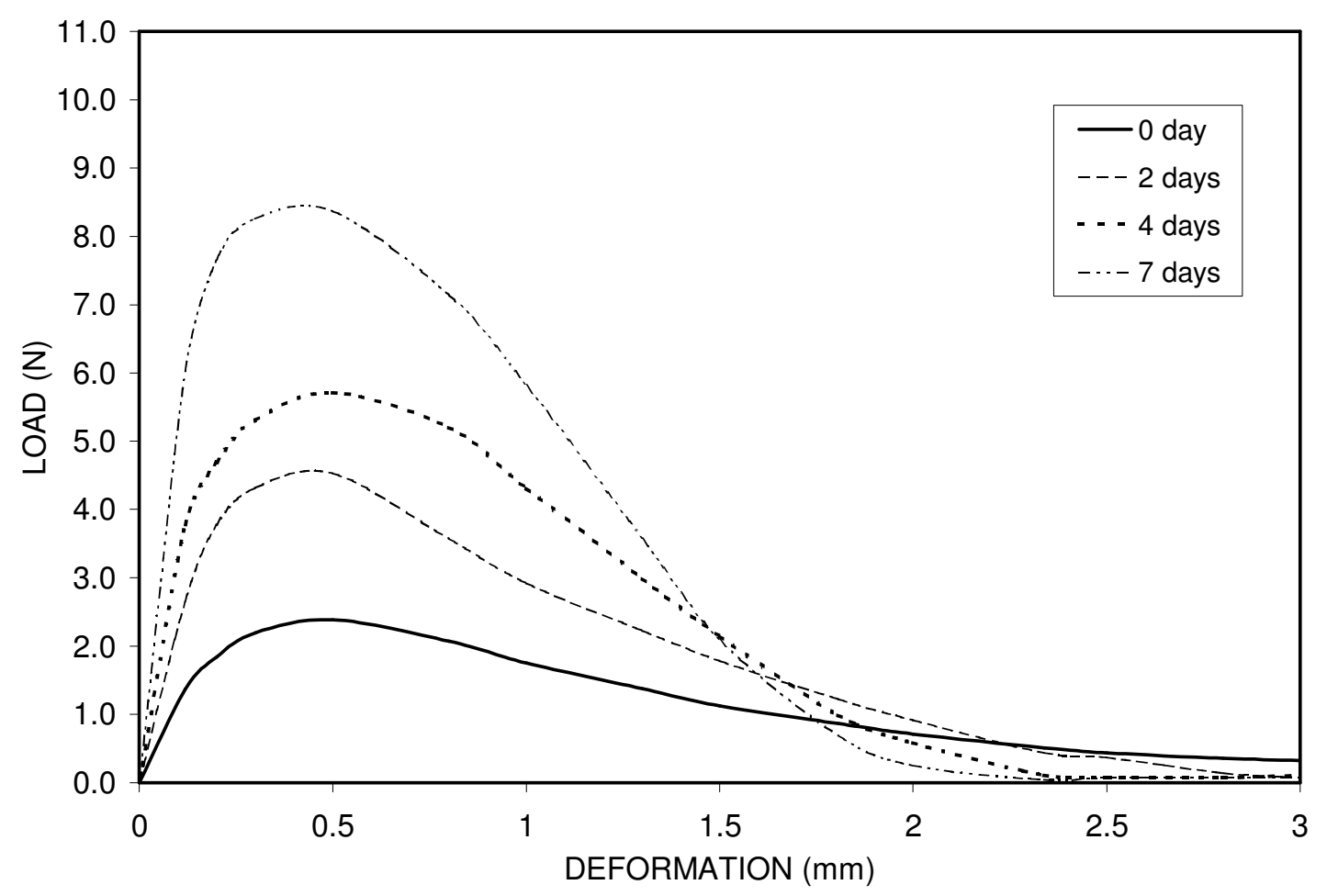


FIGURE 8. Variation of the breaking load with the volumetric concentration of filler for 0 and 7 days of aging.

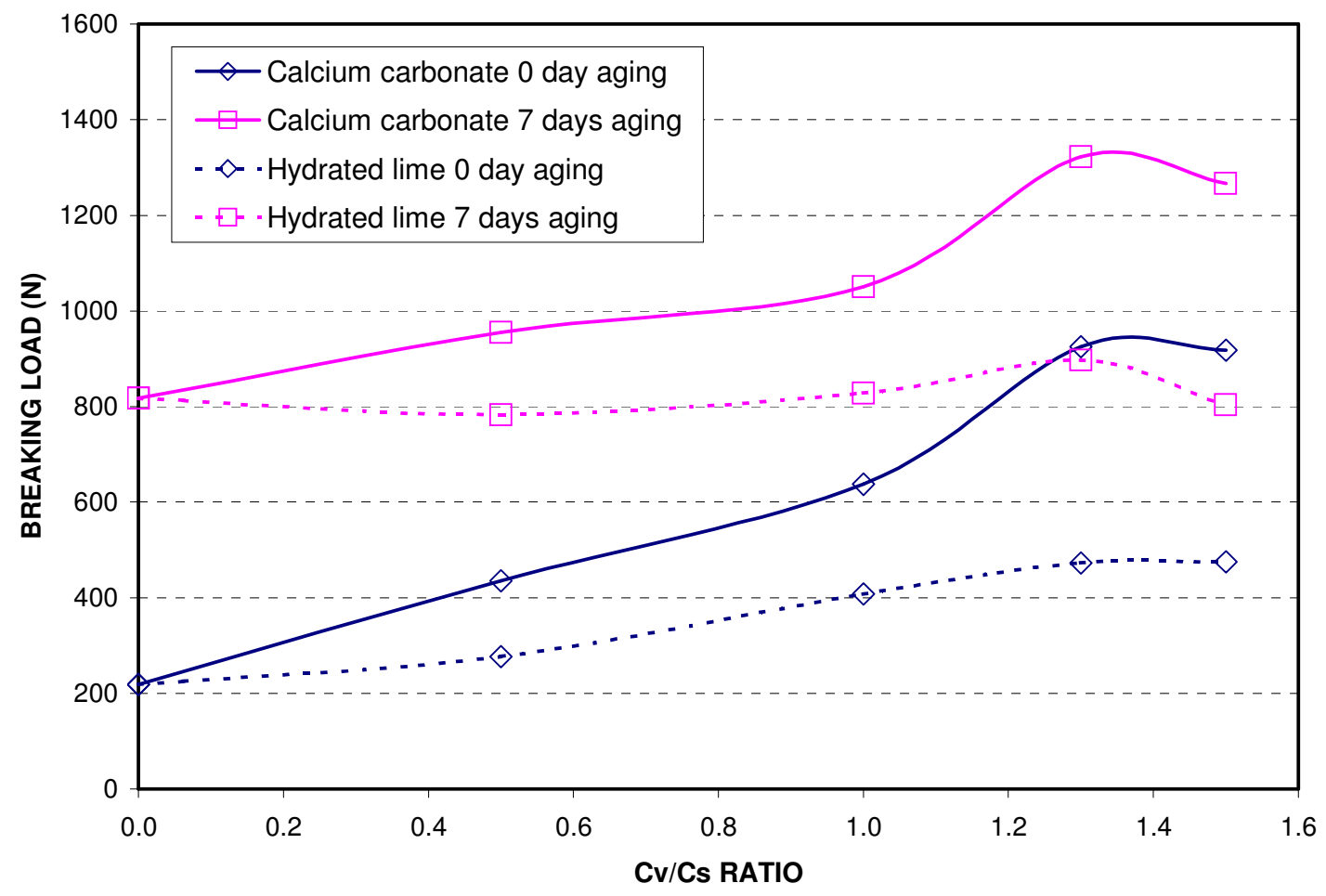


FIGURE 9. Variation of the maximum deformation with the volumetric concentration of filler for 0 and 7 days of aging.

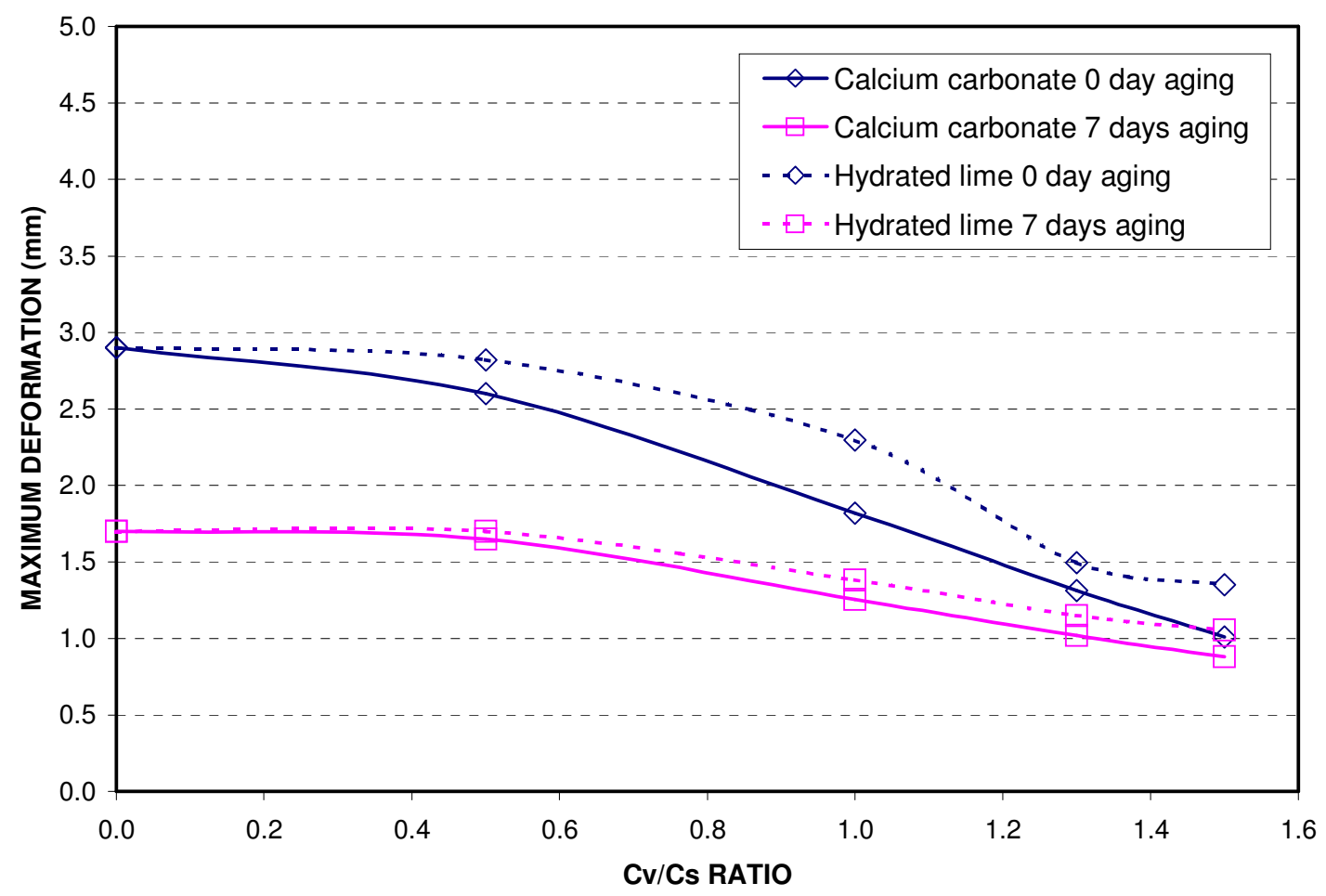


FIGURE 10. Variation of the specific energy of fracture energy with the volumetric concentration of filler for 0 and 7 days of aging.

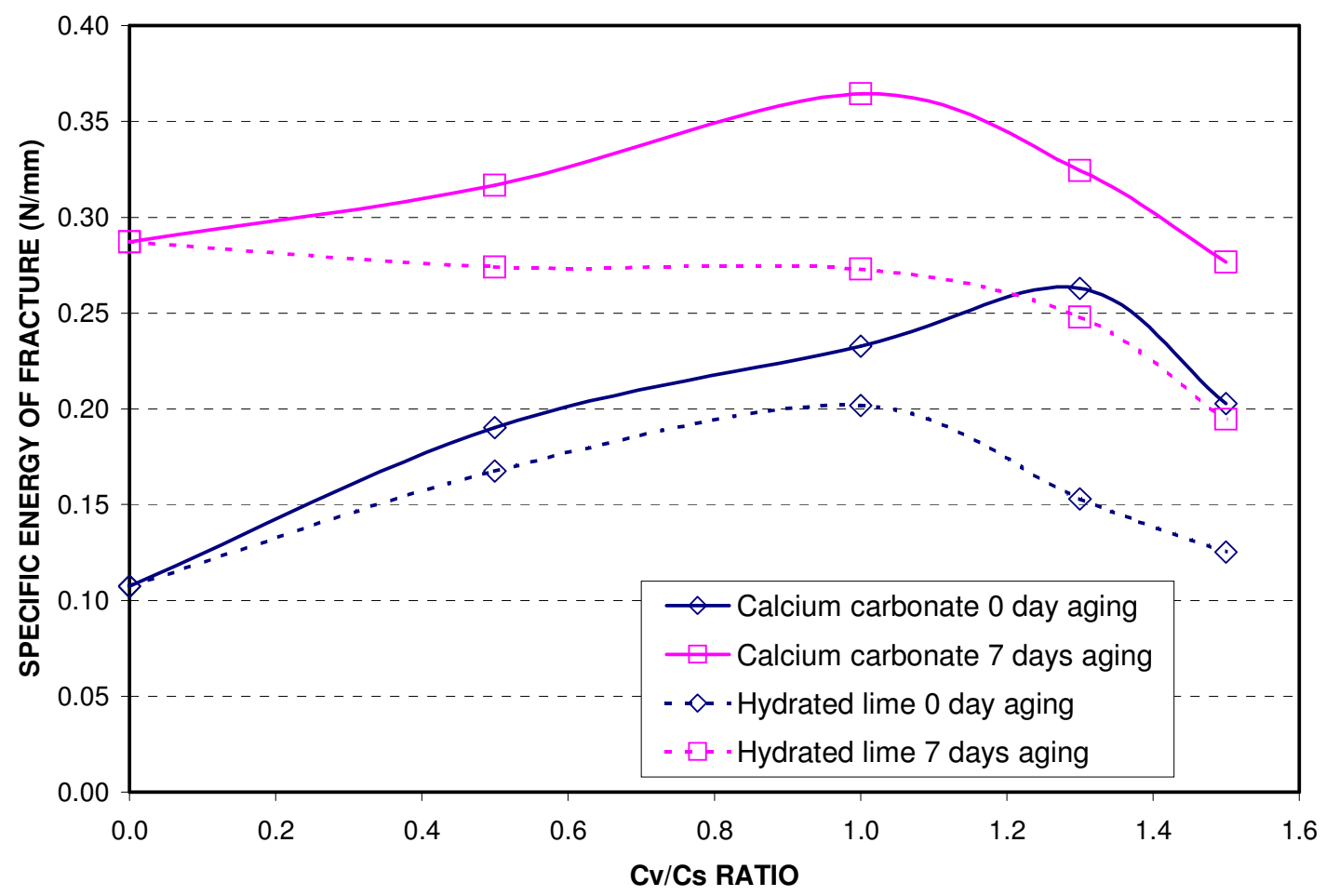

